\title{
Art Teaching in a Special School Setting: Effect on Acquisition of Academic Skills by Children with Conditions of Mental Retardation
}

\author{
Dr. Fatimah Mohammed Palmer \\ Department of Fine and Applied Arts, \\ University Of Benin, Benin City. \\ Email: Fmpalmer2256@Yahoo.Com
}

\section{Doi:10.5901/mjss.2013.v4n3p13}

\section{Abstract}

There is paucity of researches in the area of art education for children disadvantaged with conditions of mental retardation in Nigeria. This paper attempts to find out the efficacy of art teaching in enhancing the acquisition of academic skills by such children. The illustrated case study is one from a randomly selection of six pupils who made up the final sample population. Art teaching was used as an intervention strategy over a duration 104 weeks, and was found to enhance the acquisition of intellectual skills by children with conditions of mental retardation. Recommendations were made for enhancing and developing caring practices for such children.

\section{Preamble}

For two years, I taught Art at Beth Torrey Home School for children with conditions of mental retardation. One of the objectives was to verify the extent to which academic inclinations and intellectual behaviours of children with mental retardation will be facilitated through participation in art. Earlier researches on academic achievements of children with mental retardation has suggested manifestation of significant deficits in reading and mathematics (Westling: 1986, Hardman et. Al: 1990). Research has also shown that persons under this category have the capacity to move through developmental stages, as well as use art to alleviate emotional, physical and social crises (Lowenfeld: 1957; Dalley: 1990; Marriot and White: 1991).

Persons with mental retardation have been found to produce genuine artistic works, even if it is at an infantile level, such limitations are not, however reasons for short — circuiting the full creative process, and they benefit equally from art experiences as stated by Dailey (1992).

\section{Methodology}

A total of six randomly selected pupils made up the final sample population. Verification of level of retardation showed the pupils $1 \mathrm{Q}$ between $61-78$ (table 1 refers) as determined by the Toni-2 (Brown et al 1990). The profile of test result on TONI -2 indicated $1 Q$ levels $40-89$ as below normal, meaning that all the subjects operated at an educable level of mental retardation.

Table 1: 1q Level Of Sample

\begin{tabular}{|c|l|c|c|c|c|}
\hline S/no & Name & Age & Raw score & $1 \mathrm{Q}$ & \% Rank \\
\hline 1. & MaikudiZaki & 16 & 11 & 71 & 3 \\
\hline 2. & Jamilu Kano & 16 & 7 & 61 & 9 \\
\hline 3. & Auwalu Mohammed & 18 & 17 & 78 & 7 \\
\hline 4. & Yahaya Kabiru & 18 & 8 & 61 & 1 \\
\hline 5. & Aminu Garba & 18 & 17 & 78 & 7 \\
\hline 6. & Isyaku Sulaiman & 17 & 9 & 69 & 2 \\
\hline
\end{tabular}

The time series design was the frame work plan used. Data was collected by observation using a researcher designed observational schedule of art as therapy (OSAT). Pre, Peri and Post observations were taken by four observers over a period of 24 months. 
The Monart method (Brookes: 1986) of art teaching, was adapted as the teaching strategy. This method assumes that in teaching art, individuals should be regarded as having no prior knowledge of art or special talent for artistic expression, and was thus ideal for this sample population. Reaction areas observed include progress in the following:

(i) English in terms of use of vocabulary, reading comprehension and alphabetization.

(ii) Arithmetic - number counting and tendencies for calculation.

(iii) Story-telling - narrative abilities as well as understanding the story told.

(iv) Retentive memory - ability to recall.

Data collected were analyzed using averages of raw ratings by the four observers for the purpose of narrative discourse, as well as Page's $L$ trend statistical analysis, to determine if there are any differences in the trend of rating values, as can be seen in the following illustrative case.

\section{Illustrative Case: Maikudi Zaki}

Level of behavioural and intellectual functioning: 16 years old Maikudi has a 1Q Level of 71 (Table 1 refers) as determined by the TONI-2, Placing him at the educable level of mental retardation. He has partial paralysis of the right side of his body as confirmed by records of his medical diagnosis. His verbal expressions are often unintelligible due to speech difficulties. He however, makes attempts to communicate his thoughts and can be vaguely understood. He has poor finger muscle control as well as poor eye sight.

Maikudi lives at the Torrey home and has been attending the special school in the premises for about 8 years. However, he has only been able to recite the alphabet to letter ' $G$ ', and even so has difficulties identifying each letter. He could count from 1-10 in Hausa language, but made mistakes when asked to do so in English. He therefore experiences difficulties in simple arithmetical computations, Such as addition and subtraction. In Islamic studies, he could recite the first four lines of the 'fatiha', and had not progressed from that point in the 2 years before commencement of this study. Generally his intellectual functioning was rather below average.

\section{Results and Data Analysis}

Narrative discourse of data collected: Raw ratings on academic abilities arranged in predicated order. Name: - Maikudi zaki

\begin{tabular}{|c|c|c|c|c|c|}
\hline \multirow{2}{*}{ Observers } & \multirow{2}{*}{ PRE } & \multicolumn{3}{|c|}{ PERI } & POST \\
\cline { 3 - 5 } & & 1 & 2 & 3 & \\
\hline 1 & 2 & 13 & 14 & 16 & 16 \\
\hline 2 & 2 & 11 & 12 & 15 & 16 \\
\hline 3 & 1 & 10 & 12 & 14 & 15 \\
\hline 4 & 3 & 14 & 15 & 17 & 17 \\
\hline Average Rating & 2 & 12 & 13 & 15.5 & 16 \\
\hline
\end{tabular}

Table 2 shows the raw ratings by the four observers over a period of 104 weeks. The pre - observation ratings were taken before the commencement of art teaching, peri — observations ratings were done during the period of art teaching and post observation ratings, five months after termination of art teaching.

Maikudi was rated an average total of 2 points on the pre-test measurement in the cognitive domain by each of the four observers. After 5 months of art teaching his average rating dramatically increased to 12 . Six months later his rating rose to 13 . Seventeen months later, Maikudi's ratings averaged 15.5 out of 24 , at termination of art teaching. Five months later on the post - test observation, he rated an overage of 16 , indicating that cognitive skills acquired were still been retained.

Maikudi was able to recite the alphabet from $A-Z$ at this point in time, he however had difficulties with the letter LMN. He could also identify randomly chosen letters from the alphabet. In arithmetic, 5 months after commencement of art teaching, Maikudi was counting from 1-20 in Hausa language. And towards the period of termination of art teaching 17 months later, he was actually counting the numbers in English to the count of 30. He was also simultaneously computing simple additions and subtraction exercises, by counting recognizable shapes e.g.

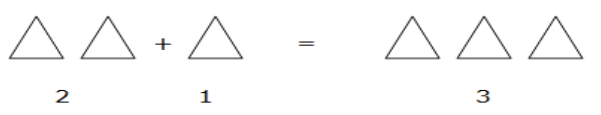


At this stage of art teaching activities, the matching warm-up exercise was being practiced repeatedly in variety of ways. This exercise involved differentiating between visual images in other to select identical shapes and forms, enabling children to be visually alert to combinations of elements, and therefore making counting of elements compulsory.

In no time at all, Maikudi was easily remembering the names of the 5 elements of shape (circle, dot, straight line, angle and curve). Familiarization with the 5 elements of shape was aimed at developing drawing abilities and enrichment of the visual perception of the environment, thereby seeing the environment from a different perception and becoming more aware of the details therein. Understanding how everything in the environment is made up of the 5 Basic elements of shape, helps in the ability to observe visual data, demystifying the drawing process, building confidence as well as enhancing the imagination. This probably helped in enhancing his retention capabilities, enabling Maikudi in remembering past experiences more easily.

Maikudi developed skills in answering questions about his everyday experiences simple questions like "what did you have for dinner yesterday?" would take him a few seconds of vacant stare, before admitting that he could not remember. This changed after several months of art teaching, and he could respond unhesitatingly in Hausa "I ate..." He had developed confidence in himself and was retaining experiences and facts in an amazing manner. Maikudi easily recounted his experience of the sallah party at the Governor's residence. This was an indication that he had progressed considerably in the area of narrative skill.

As observed by his regular class teachers, he had also developed skills in listening to stories told by a teacher, and gave correct responses to questions asked about the story, indicating an acquisition of comprehensive skill.

\section{Data Analysis}

\subsection{Collation of rating indices on academics abilities.}

The rating by each of the four observers in the academic ability reaction domain was collated following procedure based on Page's $L$ trend test principles. (Table 2 refers)

These ratings were then rank ordered following procedures based on Page's $L$ trend test principles. (Table 3 below refers).

Table 3: Table of predicted order of Ranking.

\begin{tabular}{|c|c|c|c|}
\hline 1 & 2 & 3 & 4 \\
\hline $1=(l)$ & $2=(2.5)$ & $2=(2.5)$ & $3=(4)$ \\
\hline $10=(1)$ & $11(2)$ & $13=(3)$ & $3(4)$ \\
\hline $12=(1.5)$ & $12=(1.5)$ & $14=(3)$ & $15=(4)$ \\
\hline $14=(1$ & $15=(2)$ & $16=(3)$ & $17=(4)$ \\
\hline R.value 4.5 & 8 & 11.5 & 16 \\
\hline
\end{tabular}

Figures in Parenthesis are rankings.

$E R U=(4.5 \times 1)+(8 \times 2)+(11.5 \times 3)+(16 \times 4)$

$4.5+16+34.5+64=119$

Therefore, $L=119$

Using the table of critical values of $L$, for $K=4$ and $N=4$ the minimum value of $L$ required for significance at $5 \%$ is 111. Hence there is a significant trend in the ratings of the observers about Maikudi's performance.

This, in other words mean that there is a significant difference in the trend of observed ratings of academic abilities which may be attributable to possible effects of the programme of art teaching intervention.

Five months after the termination of art teaching, the observed $L$ trend value for Maikudi was 91.5. Given the critical $L$ value of 58 at $0.05 \%$ level of significance where $K=4$ and $N=4$, it then means that academic skills acquired were retained after artistic intervention, however this depends on the 1.Q. level.

According to Gitter (1964), art plays a paramount role in alleviating emotional stress and enabling children with mental disabilities to master basic school subject to the limit of their abilities.

Brookes (1986) also asserted that "teachers often report that children who were having tremendous difficulties in school, simply improved after their successful drawing experiences without having remedial academic instruction" 
Judging from the results in table 3 , it is possible to portend that following art teaching intervention, improved academic abilities were observable in the children used for this study. This finding buttresses the findings of Wiggin, Mills \& Hebeler (1962) which indicated that significant gains were made at the primary level in arithmetic and language by children with conditions of mental retardation following experiences in art. It can be suggested therefore, that the use of the imagination as well as development of observational skills necessary for art activity in terms of formation of mental pictures may have enhanced the memory retention span of the subject and this in turn may have been transferred to other learning skills.

\section{Conclusion}

From the results of this study, it can be concluded that exposure to artistic experiences has the potential of stimulating academic zeal in children with conditions of mental retardation.

Generally, children with conditions of mental retardation were found to increasingly progress in their ability to develop academic skills as well as retaining the skills acquired after a period of art teaching.

\section{Recommendation}

It is therefore recommended that art teaching for children under this category should be made compulsory, for the purpose of enhancing and developing caring practices for them.

- Employment of art teachers should be a compulsory requirement in the staffing policy of special education schools specifically in Nigeria and generally in all developing nations.

- All teachers of primary and special education should be made to take a course in Art teaching as a minor subject to equip them with the basic skills necessary for teaching of people with conditions of mental retardation.

- Special Education teachers should be encouraged to take art education as a pre - requisite for graduation.

- Workshops for parents and teachers of children with such conditions should be organized, to sensitize them on the benefits derivable by their children through participation in artistic activities. Such workshops should include parental techniques for encouraging creative art for their children at home.

\section{Further Research Needs}

It is hoped that the result of this study will generate more curiosity and research into the area of art for children generally as well as those under these conditions. Also it will be desirable if this study is replicated in other geographical locations in Nigeria where special schools for children with mental retardation are located.

\section{References}

Brown, L; Sherbenon, R.R.; \& Johnsen S.K. (1992). Test of non-verbal intelligence: A language free measure of cognitive ability 2 Edition. Austin Texas. Pro-ed; inc.

Brookes, M. (1986). Drawing with children: A creative teaching and learning method that works for adults too. L.A: Jeremy P. Thrasher inc.

Dailey, T. (1990). Art as therapy: An introduction to the use of art as a therapeutic technique. London: Tavistock and Routledge.

Gitter. L.L. (1964). Art in a class for mentally retarded children. Bulletin of Art therapy washing ton: AATR. Vol. 3, no3, pp83-95.

Hardman, m.l; Drew, C.J, Egam M.w; \& wolf, B. (1990). Human exceptionality. (3rd Edition) mass: Allyn and Bacon.

Lowenfeld, V. (1957), Creative and mental growth. 3rd Edition. New-York Macmillan publishes Co. Inc.

Marriot, B. \& white, P.m. (1991). The impact of Art on the life of a woman who was mentally retarded. American Journal of Art therapy. Vol. 30, 10-16.

Page E.E. (1963). "Application of $L$ - trend statistics to psychological data". Journal of American statistical Association. 58, 216-30.

Ulman, E. (1992). Art education for the emotionally disturbed? American Journal of Art therapy. Vol. 30

Westling, D (1986). Introduction to mental retardation. Engiewood cliffs. NJ: prentice Hall. Inc.

Wiggin. R; mills, E; Habeler, J (1962). Teaching mentally handicapped children through art. Art Education Bulletin. New York: vol. 19 (5) $20-24$. 